\title{
Analysis of the Influence of Informal Network of Industrial Clusters on the Training of Technical and Skilled Talents
}

\author{
Ren-Zhen MENG ${ }^{1 \mathrm{a}}$ \\ ${ }^{1}$ (Higher Education Institute, Shanghai Publishing and Printing College, Shuifeng Road 100, \\ Shanghai, China) \\ a365488147@qq.com \\ ${ }^{*}$ Corresponding author
}

Keywords: Industrial Cluster, Informal Network, Technical and Skilled Talents, Tacit Knowledge

\begin{abstract}
There is an informal network formed by informal contacts in industrial clusters. This informal network plays an important role in the dissemination and spillover of tacit knowledge. The knowledge structure of technical and skilled talents is mainly a large amount of skill-type tacit knowledge, which is characterized by high content of tacit knowledge. Therefore, informal networks formed by clusters of industrial clusters play an important role in the dissemination of skilled knowledge and the training of skilled and skilled technical and skilled talents. Based on the analysis of the informal network, tacit knowledge of technical and skilled talents, and the model of "learning by doing”, this paper gives relevant suggestions.

As a social network, as its name implies, the informal network is a communication network that is different from formal network. Informal networks have features such as spontaneity, looseness and diversity. Informal networks act like organisms' nervous systems. The forming power of informal networks stems from the closeness of social relations between members, such as kinship, business relationship, friendship, and similar interests and hobbies. Emotion and other factors are an important foundation for its existence. In fact, industrial cluster is a complex that contains a variety of relational networks. Industrial clusters and informal networks have close links with the dissemination and accumulation of skilled knowledge and the cultivation of skilled talents.
\end{abstract}

\section{Skilled knowledge has a distinctive feature with high degree of tacit}

Based on Polanyi's classification of knowledge, knowledge can be classified into explicit knowledge and tacit knowledge according to the degree to which it can be coded. Tacit knowledge can be divided into mental tacit knowledge and action tacit knowledge. The knowledge and skills acquired by technical and skilled talents often come from the practice of production, including long-term experience, know-how and unique skills accumulated in the development and innovation of technical skills. This type of knowledge can only be revealed in actual operation, and it is difficult to directly code and hardly to be highly explicit. It's perceived rather than expressed. Such tacit knowledge possessed by technical and skilled talents is the core competence with which technical and skilled talents and their companies and industries can survive and become strong

How to inherit and innovate such tacit knowledge is also an important guarantee for industrial clusters to maintain vitality and sustainable development. For example, in many areas of our country, unique skills with strong regional labels and derived specialty industries and specialty products have been formed in long-term production practices. Such examples are numerous, such as Suzhou

\footnotetext{
${ }^{1}$ Fund Project: Research Innovation Project of the Shanghai Municipal Education Commission (Humanities and Social Sciences) has been approved, it is a "A Study on Cooperation Model of Industry Cluster and Vocational Education Group under the Perspective of Regional Innovation Network” (No. 13YS148); Shanghai Municipal Education Commission’s Educational Science Research Project "Development Path of Vocational Education in the Context of the Transformation and Upgrading of Industrial Structure in Shanghai: Spatial Agglomeration and Structural Coupling” (No. B12075) . About the author: Renzhen Meng, lecturer and Ph.D. of Renmin University of China, Research Direction: Vocational Education, Regional Economy.
} 
Embroidery, Jingdezhen porcelain and ceramics, three kinds of knives in Yangzhou, Beijing Cloisonné and so on. The regional embeddedness of these industries stems from the highly tacit sense of the skills that these industries rely on. An important prerequisite for the learning and transmission of these higher-level skills with a tacit understanding is direct contact and mutual communication between people. The tacit degree of the initial skills of these industries also determines the spatial locking characteristics and historical evolution of the industry.

In addition to the above-mentioned skill-oriented tacit knowledge, there is a tacit knowledge that cannot be ignored. That is the "mental aura of a master which is deeply embedded in a skillful craftsman or a manual craftsman. Actually, this kind of "mental aura" is the human strength, which is now often referred to as the "professional quality" and "professionalism" or "craftsmanship spirit". Sometimes, this kind of spirit and attainment may appear as an inadvertent habit or convention, but this is originate from the inheritance, accumulation, and repeated practice of generations. These attainment, spirit, emotion, will or qualities are tacit knowledge of the mind have been integrated into the blood of craftmen. To a certain extent, the mental tacit knowledge is even more than the action skill-oriented tacit knowledge. It is necessary to "taste" "perceive" and experience.

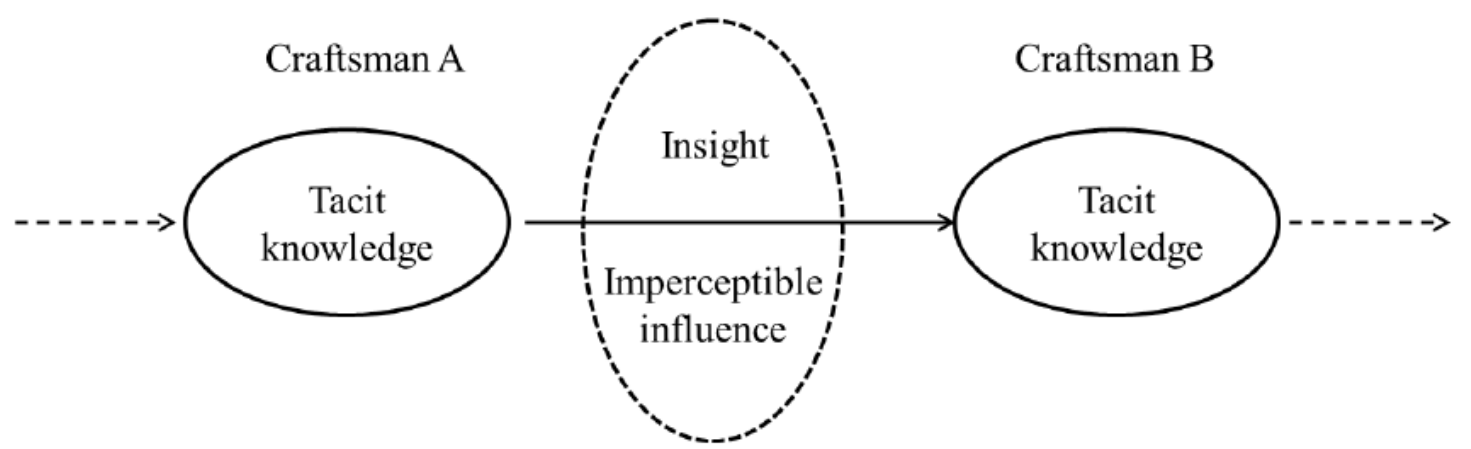

Figure 1 The main transformation path of the traditional craftsman's tacit knowledge

\section{“Learning by doing” is an important way to learn skill-oriented tacit knowledge}

The learning and dissemination of explicit knowledge is different from classroom-oriented teaching. The hard-to-encode characteristics of skilled-oriented tacit knowledge determine that their learning and communication are generally inseparable from face-to-face communication. Moreover, the skilled-oriented tacit knowledge has the characteristics that it needs to be practiced and operated on site. For example, knowledge of "how to ride a bicycle" is difficult to obtain through books and classroom, and it is necessary for the master to guide the apprentice in repeated field practices. Kenneth Arrow had established the theory of "learning by doing" based on the accumulation of human capital. The theory played an important role in explaining the technological advance at the national level. In fact, "learning by doing" is the same as education and training, and it is also an important way to accumulate human capital, especially the accumulation of skill-oriented human capital. In the process of accumulation of human capital for skilled talents, knowledge dissemination, skills learning and experience accumulation can be achieved in practice through the form of "learning by doing" and face-to-face, hand by hand demonstration and imitation. In the process of "learning by doing”, in addition to the acquisition of knowledge and skills, the more important for the apprentice is the longitudinal inheritance of mental tacit knowledge such as professional qualities and craftsman spirit.

Western developed countries attach great importance to the skills teaching model of "learning by doing" in the practice of modern vocational education. For example, the German Dual System, the British Apprenticeships, and Australia's TAFE model, all emphasize the effect of "learning by doing" on the skills learning process in the field environment and apprentices can only obtain knowledge after practicing repeatedly in the company's real production practice. At present, the logical starting point of the modern apprenticeship system that is being vigorously promoted in China is to create a 
genuine training environment for the training of technical and skilled talents. Of course, modern apprenticeship as a pilot, and there are not many specialties and people that can be covered currently. The school in the factory and factory in the school which are established by school-enterprise cooperation could be an important supplement. Some demonstrative vocational colleges have set up industrial parks by relying on characteristic specialties and industrial factors have been gathered. In the industrial parks, the school encourages and guides students to innovate and start up business through policy support and teacher guidance. Actually, it is a vivid practice of the "learning by doing" model. When the industry clusters reach to a certain degree, it will release a strong agglomeration effect and produce positive externalities. This externality can be nurtured into teaching. The newly incubated enterprises have become site for practical teaching and have become teaching resources. Successful entrepreneurs become part-time teachers of the colleges. The agglomeration of industrial factors gave birth to the agglomeration and expansion of teaching elements. The mutual support of teaching elements and industry factors has formed a benign and interactive model of "learning by doing”.
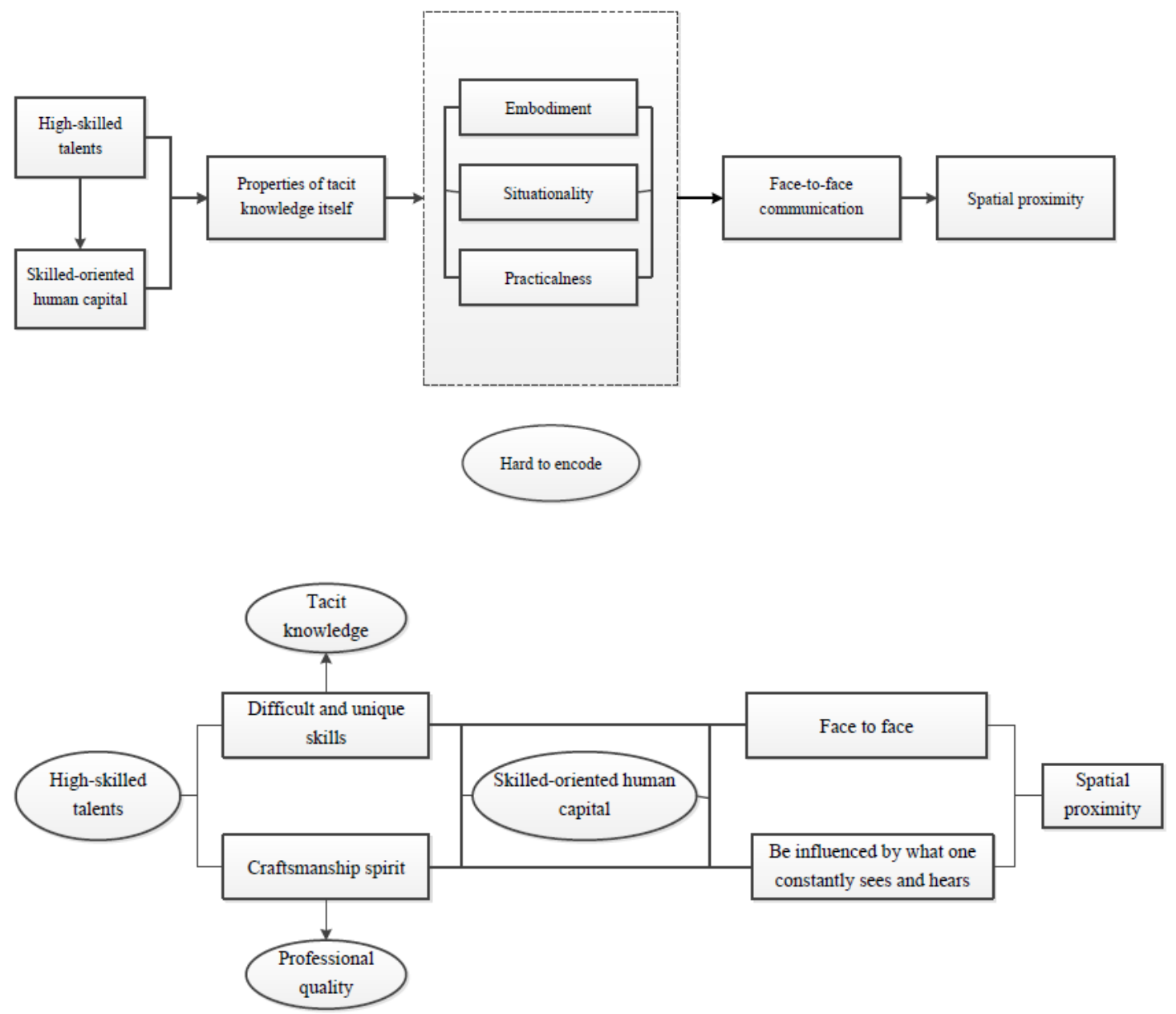

Figure 2 The main connotation of skilled human capital and its relationship with spatial agglomeration

\section{Informal networks are key platforms for learning and innovation of tacit knowledge}

Like the "Unintentional positive outcomes". It is the informality and casualness of various links in informal networks that make informal networks important for the dissemination and spillover of tacit knowledge of technical and skilled talents. The recessive feature of tacit knowledge makes the dissemination and innovation of such knowledge require more exchanges and collisions. The informal features of the informal network make it more advantageous in the interaction of the subject. Geographic proximity is an important prerequisite for the informal network to function. Within a certain range, the density of talent accumulation and the efficiency of spillover and dissemination of 
tacit knowledge and the extent to which informal network functions are exerted are proportional. The clustering characteristics of industrial clusters are in line with this demand. In industrial clusters, the agglomeration of enterprises has brought a large number of technical and skilled talents together within a certain geographic scope. The spatial density of talents has increased their chances of contact and communication, creating conditions for "learning by doing". Informal exchanges such as a gathering of friends or a few friends sipping together for coffee may provide opportunities for new technological skills innovations. Because the characteristics of professional talents in the industry cluster are similar to each other, their topics may also be focused on a certain professional field. This is conducive to the emergence of new technologies and new processes. At present, many universities and colleges have opened "coffee houses" and other exchange place on campus, which actually create conditions for the formation of informal networks.

At the same time, an important factor in the functioning of informal networks is the embeddedness of cultural. There are similarities in regional culture, industrial culture, and skill culture among various entities in an informal network of industrial clusters. The difference from the economic contractual relationship in the formal network is that the informal networks established a kind of social trust relationship which is on the basis of cultural similarity. Based on this trust relationship, the obstacles in the dissemination of tacit knowledge are reduced, and the path of knowledge transfer of technical and skilled talents will be smoother. On the basis of high interpersonal trust, the owners of skills such as tacit knowledge will have weaker concerns and worries about "teach apprentice how to do, make master starve to death". To a certain extent, it also improves the efficiency and quality of skill-oriented tacit knowledge dissemination.

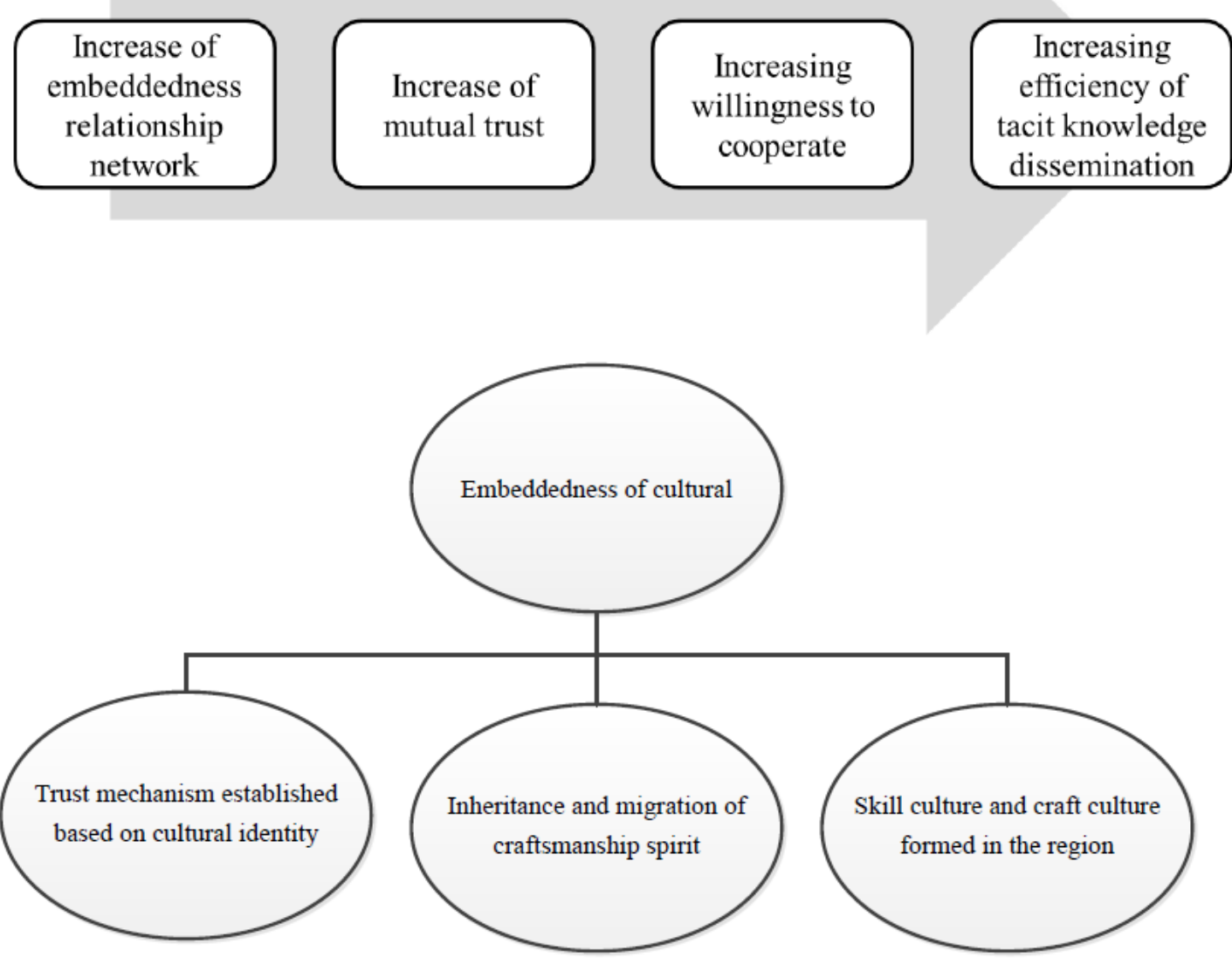

Figure3 Factors affecting the concentration of highly skilled talents by cultural embeddedness 


\section{Conclusion and Suggestions}

From this we can see that the tacit knowledge of technical and skilled talents with high degree of tacit contains two types of skills and qualities. No matter what kind of tacit knowledge, the "learning by doing" model that highly relies on practice is an effective way of learning. The high density of contact frequencies, smooth communication mechanisms, and high levels of trust between people based on informal networks of industrial clusters have had a significant positive effect on the dissemination and innovation of technological skill-oriented tacit knowledge, and have important guiding significance for the training of technical and skilled talents.

For skills learners, attention should be paid to the importance of apprenticeships, especially the importance of professional qualitities, craftsmanship, and charisma embodied in the masters. We must emphasize the role of practice in skills learning, and be more operations and more understanding. People can master skills only by combining hands and brains; attention should also be paid to the role of various informal exchanges in the process of improving their skill levels, participating in various salons, and learning skills from others. For the university level, as an important subject for the cultivation of technical and skilled talents, the scale and density of technical and skilled talents should be further increased, resulting in scale effect and agglomeration effect; the proportion of teaching in the process of talent cultivation should be further practiced, and the quality of practical teaching will be improved. Further external material support should be provided for the formation of informal networks. As an industrial agglomeration area, attention should be paid to digging and carrying forward the unique local culture, industrial culture and skill culture, and provide strong cultural support for the development of industrial clusters. This is because it is the cultural soil created by the tacit knowledge in clusters and regions. What is different from the trans-regional migration of enterprises is that these cultural connotations are difficult to simply copy and migrate in other regions; it is the source of knowledge and skills for sustainable development in the region; it is the lubricant for the dissemination of tacit knowledge in the region, and it is the catalyst for spillover of tacit knowledge and it is where the regional soft power and core competitiveness lie.

\section{References}

[1] Qin Tiehui, Sun Lin. Discussion on Informal Network and Its Role in Knowledge Sharing Activities [J]. Information Science, 2009, 27(1):15.

[2] Wang Jici. Space for Innovation-Enterprise Clusters and Regional Development [M]. Beijing: Peking University Press, 2001.

[3] Sun Yangyang, Wang Shouning. Obstacles and Countermeasures of Tacit Knowledge Sharing in Enterprises [J]. Information Science, 2009, 27(9):134-134.

[4] Peng Yifeng. Characteristics of Talent Demand in China's Industrial Clusters and Structural Optimization of Higher Vocational Education, Higher Engineering Education Research, 2007(1): 27-29.

[5] Zhang Guomin, Zhang Hao, Chen Jin. Research on the Function of Human Capital in the Evolution and Development of Industrial Clusters [J]. Business Vitality, 2011(5). 